\title{
A study on consolidated composite adsorbents for cooling application
}

\author{
Ibrahim I. El-Sharkawy ${ }^{1,3,5,{ }^{*}}$, Animesh Pal $^{2}$, Takahiko Miyazaki ${ }^{1,5}$, \\ Bidyut Baran Saha ${ }^{2,4,5}$, Shigeru Koyama ${ }^{1,4,5}$ \\ ${ }^{1}$ Faculty of Engineering Sciences, Kyushu University \\ Kasuga-koen 6-1, Kasuga-shi, Fukuoka 816-8580, Japan \\ ${ }^{2}$ Kyushu University Program for Leading Graduate School, Green Asia Education \\ Center, Interdisciplinary Graduate School of Engineering Sciences, Kyushu University, \\ Kasuga-koen 6-1, Kasuga-shi, Fukuoka 816-8580, Japan \\ ${ }^{3}$ Mechanical Power Engineering Department, Faculty of Engineering \\ Mansoura University, El-Mansoura 35516, Egypt \\ ${ }^{4}$ Interdisciplinary Graduate School of Engineering Sciences, Kyushu University \\ Kasuga-koen 6-1, Kasuga-shi, Fukuoka 816-8580, Japan \\ ${ }^{5}$ International Institute for Carbon-Neutral Energy Research (WPI-I2CNER), Kyushu \\ University, 744 Motooka, Nishi-ku, Fukuoka 819-0395, Japan \\ *Author to whom correspondence should be addressed, E-mails: \\ ielsharkawy@mans.edu.eg \\ ielsharkawy@phase.cm.kyushu-u.ac.jp
}

Tel: $+81-92-583-7832 \quad$ Fax: $+81-92-853-7833$

\begin{abstract}
In this study, consolidated composite adsorbents which are combinations of a highly porous activated carbon powder (Maxsorb III), expanded graphite (EG) and binder have been developed and characterized. Porous properties of the developed composite adsorbents have been investigated experimentally using Nitrogen adsorption. Adsorption equilibrium uptakes of ethanol onto composite adsorbents have been measured and correlated using suitable adsorption isotherm models. Thermal
\end{abstract}


conductivity of the prepared adsorbents has also been measured using the NETZSCH LFA 457 MicroFlash system. Experimental results show that the adsorption equilibrium capacity of ethanol onto consolidated composite (70\% Maxsorb III, 20\% EG, 10\% binder) is $0.89 \mathrm{~kg} \mathrm{~kg}^{-1}$ which is about $74 \%$ of the maximum adsorption uptake of parent Maxsorb III/ethanol pair. This is a clear evidence that the binder doesn't sacrifice the adsorption capacity of Maxsorb III of consolidated composites. It is also found that the thermal conductivity of the developed consolidated adsorbents increased to 10 times that of Maxsorb III powder.

Keywords: Adsorption cooling; Adsorption characteristics; Consolidated adsorbents;

Ethanol

\section{Nomenclature}

$\mathrm{C}_{\mathrm{p}} \quad$ specific heat capacity $\left(\mathrm{J} \mathrm{kg}^{-1} \mathrm{~K}^{-1}\right)$

d diameter (m)

E adsorption characteristics parameter $\left(\mathrm{kJ} \mathrm{kg}^{-1}\right)$

h height $(m)$

$\mathrm{k} \quad$ thermal conductivity $\left(\mathrm{W} \mathrm{m}^{-1} \mathrm{~K}^{-1}\right)$

L thickness of the tested sample (m) 


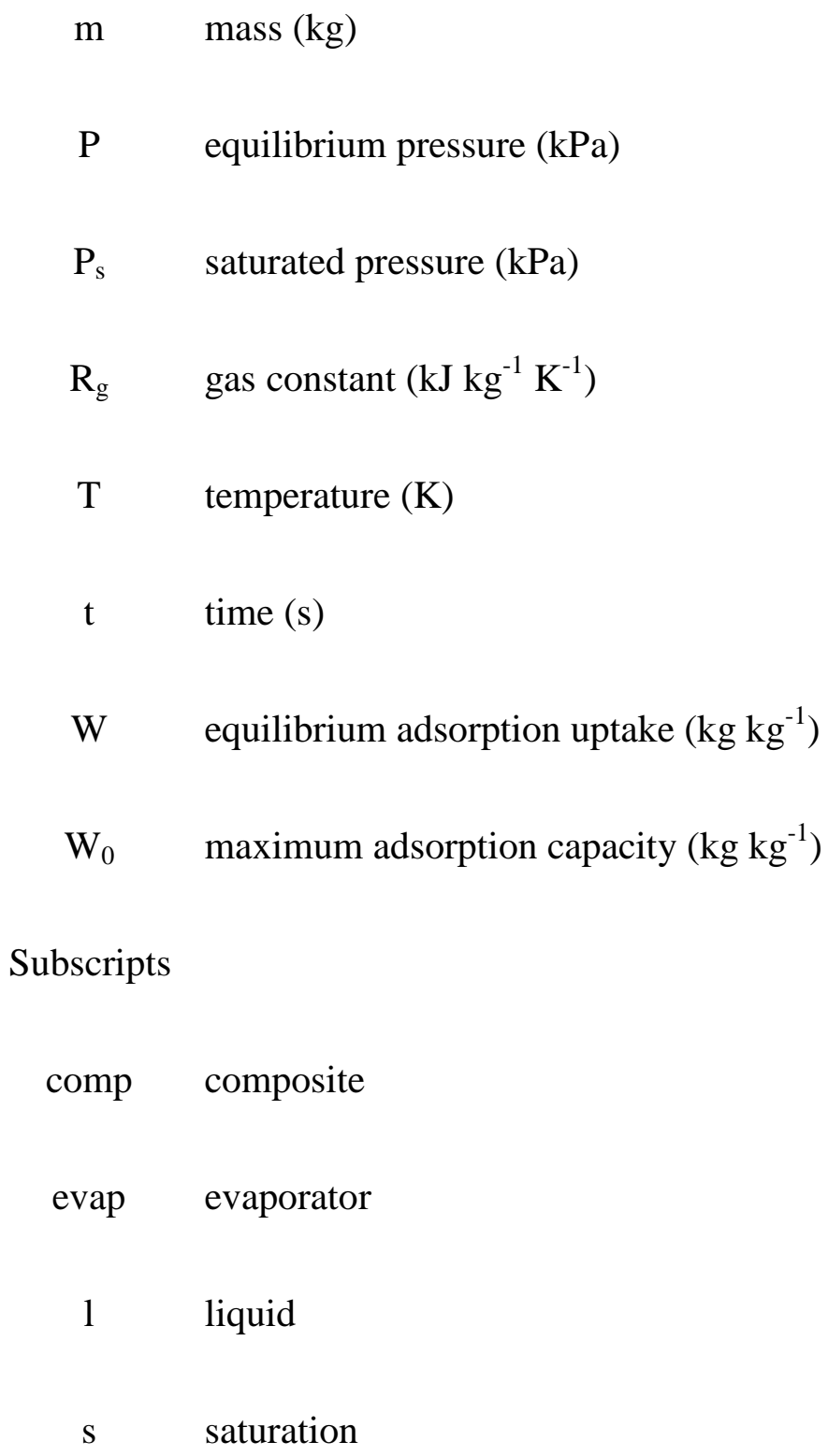

Greek symbols

$$
\begin{aligned}
& \alpha \quad \text { thermal diffusivity of composite adsorbents }\left(\mathrm{m}^{2} \mathrm{~s}^{-1}\right) \\
& \rho \quad \text { density }\left(\mathrm{kg} \mathrm{m}^{-3}\right)
\end{aligned}
$$

\section{Introduction}

Global warming and Ozone layer depletion are serious environmental problems that call 
for prompt worldwide actions. Vapor compression systems using CFCs, HCFCs and HFCs are among the primary causes of these phenomena. Therefore, the need for switching to Freon-free air conditioning technologies has become an urgent necessity. Thermally powered adsorption cooling systems seems to be a promising alternative of conventional vapor compression cycles. The main advantages of these systems are; (i) they can be driven using low temperature heat source, (ii) they use natural refrigerants such as water, ethanol and methanol, and (iii) almost no electricity usage [1]. However, the main drawback of these systems is their low performance in terms of COP and cooling capacity. Intensive research efforts have been devoted to improve the system performance, for instance, using promising adsorbent/refrigerant pairs [2-12] and optimizing the operation strategy of adsorption cycles [1, 13, 14]. Heat transfer intensification through the adsorbent bed is also one of the most effective methods for developing high performance cooling systems due to the poor heat transfer between adsorbent particles. In the past years, consolidated adsorbents attracted attention of many researchers as a possible solution of heat transfer enhancement in the adsorber/desorber reactor. Following are some representative examples. Cacciola et al. [15] developed brick shaped adsorbent materials based on activated carbons and PTFE (poly-tetra-fluorethylene) as a binder. They reported that the adsorption capacity of methanol onto the developed adsorbents is higher than $40 \%$ and the thermal conductivity ranging from 0.13 to $0.20 \mathrm{~W} \mathrm{~m}^{-1} \mathrm{~K}^{-1}$. Jin et al. [16] tested thermal conductivity and permeability of granular activated carbon (AC), consolidated AC with chemical binder and consolidated AC with expanded natural graphite. The authors reported that thermal conductivity of granular activated carbon, and consolidated activated carbon with chemical binder are about $0.36 \mathrm{~W} \mathrm{~m}^{-1} \mathrm{~K}^{-1}$ and $0.4 \mathrm{~W} \mathrm{~m}^{-1} \mathrm{~K}^{-1}$, 
respectively. Thermal conductivity of consolidated activated carbon with expanded natural graphite ranging from $2.08 \mathrm{~W} \mathrm{~m}^{-1} \mathrm{~K}^{-1}$ to $2.61 \mathrm{~W} \mathrm{~m}^{-1} \mathrm{~K}^{-1}$, however, its permeability is lower than that of the granular AC and consolidated AC with chemical binder. Tamainot-Telto et al. [17] measured the thermophysical properties of two types of monolithic activated carbons. The authors reported that the thermal conductivity of the tested samples is $0.44 \mathrm{~W} \mathrm{~m}^{-1} \mathrm{~K}^{-1}$ and the adsorption capacity for ammonia is $0.36 \mathrm{~kg}$ $\mathrm{kg}^{-1}$. Wang et al. [18] developed composite adsorbents which are combinations of activated carbon and expanded natural graphite. Thermal conductivity and permeability have been experimentally investigated. They reported that the best values of measured thermal conductivity and permeability are $2.47 \mathrm{~W} \mathrm{~m}^{-1} \mathrm{~K}^{-1}$ and $4.378 \times 10^{-12} \mathrm{~m}^{2} \mathrm{~s}^{-1}$, respectively. Wang et al. [19] developed consolidated composite activated carbon (AC) with a host matrix of expanded natural graphite treated with sulfuric acid (ENG-TSA). The authors reported that the highest effective thermal conductivity of consolidated composite $\mathrm{AC}$ was $34.2 \mathrm{~W} \mathrm{~m}^{-1} \mathrm{~K}^{-1}$ which was 150 times higher than ordinary granular activated carbon. Zheng et al. [20] proposed composite desiccant adsorbent that comprises silica gel silica gel with expanded natural graphite treated with sulfuric acid (ENG-TSA) as a host matrix. It is reported that the highest thermal conductivity of consolidated composite adsorbents increased more than 270 times as compared to that of pure silica gel. Other related research work can be found elsewhere [21-25]

The highly porous activated carbon powder (Maxsorb III) proven that it has promising adsorption characteristics with the refrigerant ethanol $[8,26]$. However, a literature review indicated that there is a dearth of accurate data on the adsorption characteristics of ethanol onto consolidated Maxsorb III. The motivation of this study is to conduct 
detailed experimental investigations of; (i) development of consolidated composite adsorbents which comprises a highly porous activated carbon powder namely Maxsorb III, expanded graphite and a binder, (ii) porous properties of the prepared samples, (iii) adsorption characteristics of ethanol onto the prepared consolidated adsorbents, (iv) thermal conductivity of the studied adsorbents.

\section{Experiments}

\subsection{Materials}

The key material used for preparing consolidated composite adsorbents is activated carbon powder, namely Maxsorb III provided by Kansai Coke \& Chemicals Co. Ltd., Japan. It has a surface area and pore volume as high as $3045 \mathrm{~m}^{2} \mathrm{~g}^{-1}$ and $1.7 \mathrm{~cm}^{3} \mathrm{~g}^{-1}$, respectively [8]. Expanded graphite (EG) namely EC500 supplied by Ito Graphite Industries Co., Ltd., Japan is used to increase the thermal conductivity of composite adsorbents. Polyvinyl Alcohol (PVA) 500 supplied by Kanto Chemical Co., Inc., Japan is used as a binding material. The refrigerant used herein is ethanol (99.5\% purity) supplied by Osaka Kishida Chemical Co. Ltd., Japan.

\subsection{Preparation of composite adsorbents}

Fig. 1(a) shows the production process of the composite adsorbents. The process can be explained as follows; firstly, Maxsorb III and expanded graphite are dried in the oven at a temperature of $120{ }^{\circ} \mathrm{C}$ for about 6 hours to eliminate the moisture content. The binder which exists in a powder form is mixed with water where it turns into solution. Maxsorb III and expanded graphite powders, with certain ratios, is then mixed with the binder solution. It should be highlighted that mass of water is almost two times the total mass 
of Maxsorb III, expanded graphite and binder powders. After that, the mixture is compressed using a pressing machine. Finally, the composite adsorbent samples are dried in the oven at a temperature of $120^{\circ} \mathrm{C}$ for about 10 hours. Two types of composite samples have been prepared based on the sample mass and size. The first type is used for ethanol adsorption uptake measurements where the dry samples mass is about $2 \mathrm{~g}$ and diameter is $20 \mathrm{~mm}$ whilst the sample height ranging from $12 \mathrm{~mm}$ to $15 \mathrm{~mm}$ based on the composition of composite. The second type is used for Nitrogen adsorption and thermal conductivity measurements. A series of composite samples has been prepared where the samples dry mass is about $0.2 \mathrm{~g}$, diameter is $17 \mathrm{~mm}$ and height ranging from 1.1 to $1.6 \mathrm{~mm}$. A pictorial view of developed composite adsorbents is shown in Fig. $1(b)$.

\subsection{Porous properties}

The porous properties including total surface area, total pore volume, and pore size distribution of the prepared composite adsorbents named A, B, C, and D have been estimated using Nitrogen adsorption. The compositions of the developed samples have been furnished in Table 1. Figure 2 shows the $\mathrm{N}_{2}$ adsorption/desorption isotherm of the studied composite adsorbents. As can be seen from Fig. 2, the amount of Nitrogen adsorbed increases with the increase of the percentage of Maxsorb III and no hysteresis has been observed. The surface area of each composite adsorbent has been investigated using Brunaure-Emmett-Teller (BET) method whilst the Non-Local Density Functional Theory (NLDF) has been used to estimate the total pore volume. The pore size distribution analysis using the NLDF theory for composite adsorbents $\mathrm{A}, \mathrm{B}, \mathrm{C}$, and D are presented in Fig. 3 and results showed that their range of pore diameters is between 
$10 \AA$ and $35 \AA$. Numerical values of the total surface area and total pore volume of the tested composites have been presented in Table 1. It should be highlighted that the porous properties of the tested composites in terms of surface area and pore volume depends mainly on the percentage of the Maxsorb III.

\subsection{Adsorption uptake measurements}

The experimental apparatus for measuring adsorption uptake of ethanol onto the developed composite adsorbents composes mainly an adsorber, an evaporator, two constant temperature water baths, and two water circulators as shown in Figure 4. Adsorber is a small stainless steel cylinder of $40 \mathrm{~mm}$ diameter and $40 \mathrm{~mm}$ height whilst $\mathrm{K}$-type thermocouple is inserted to measure adsorbent temperature. The evaporator is a glass tube of $10 \mathrm{~mm}$ outer diameter, $1.6 \mathrm{~mm}$ wall thickness and $174 \mathrm{~mm}$ height where K-type thermocouple is inserted to measure the evaporator temperature. Two constant temperature water baths of type TBN302DA along with two water circulators of type CTP3000 have been used to control the adsorber and evaporator temperatures. A rotary vacuum pump of type ULVAC (GCD-136X) has been used to evacuate the system. A Pirani gauge of type PG-D5A is used to test the vacuum condition of the system whilst AP10-32 type pressure transducer is used to measure the system pressure. A digital microscope of type NRM-D-2XZ with a minimum resolution of $0.01 \mathrm{~mm}$ has been used to measure the height of ethanol level in the evaporator before and after conducting adsorption process. Weight of adsorbent samples has been measured using Sartorius Practum 124-1S analytical lab balance with 120 grams weight capacity and readability of $\pm 0.1 \mathrm{mg}$. To avoid any condensation during the adsorption process, a tape heater surrounds the connecting tubes between evaporator and adsorber. 
The experimental procedure can be summarized as follows:

i) Prior to conducting adsorption uptake measurements, the composite adsorbent is dried using an oven for about 12 hours at $120{ }^{\circ} \mathrm{C}$. After that, the sample weight is measured.

ii) The composite adsorbent is then placed into the adsorber and regenerated under vacuum condition for more than 3 hours at a temperature of $80{ }^{\circ} \mathrm{C}$.

iii) The evaporator temperature is kept constant at $5{ }^{\circ} \mathrm{C}$ whilst the adsorber temperature is maintained at $70{ }^{\circ} \mathrm{C}$. The height of ethanol onto the evaporator is then measured using the digital microscope. Valve between the evaporator and adsorber is opened where ethanol vapor flows to the adsorbent sample. After reaching the equilibrium condition, the ethanol height inside the evaporator is measured again to determine the amount of ethanol adsorbed.

iv) Valve between the evaporator and adsorber is closed and the adsorber temperature is cold down to $60{ }^{\circ} \mathrm{C}$. The valve is then opened and adsorption process is carried out. The same procedure is repeated at adsorption temperatures of $50,40,30$ and $20{ }^{\circ} \mathrm{C}$.

v) To measure the isobaric adsorption corresponding to the evaporator temperature of $10{ }^{\circ} \mathrm{C}$ and $15^{\circ} \mathrm{C}$, steps (i) and (iv) have been repeated.

\section{Uncertainty analysis}

The uncertainty in ethanol adsorption uptake measurements $\left(\mathrm{kg} \mathrm{kg}^{-1}\right)$ based on the experimental test rig shown in Fig. 4 has been estimated using Eq. (1). The experimentally measured adsorption uptake and the corresponding derivatives are also given by Eqs. 1(a)- 1(d) below [27]; 


$$
\begin{aligned}
& \delta W=\sqrt{\left(\frac{\partial W}{\partial d_{\text {evap }}} \delta d_{\text {evap }}\right)^{2}+\left(\frac{\partial W}{\partial m_{\text {comp }}} \delta m_{\text {comp }}\right)^{2}+\left(\frac{\partial W}{\partial h_{\text {evap }}} \delta h_{\text {evap }}\right)^{2}} \\
& W=\rho_{l} h_{\text {evap }} \frac{\pi}{4}\left(\frac{d_{\text {evap }}^{2}}{m_{\text {comp }}}\right) \\
& \frac{\partial W}{\partial d_{\text {evap }}}=\rho_{l} h_{\text {evap }} \frac{\pi}{4}\left(\frac{2 d_{\text {evap }}}{m_{\text {comp }}}\right) \\
& \frac{\partial W}{\partial m_{\text {comp }}}=-\rho_{l} h_{\text {evap }} \frac{\pi}{4}\left(\frac{d^{2}{ }_{\text {evap }}}{m_{\text {comp }}^{2}}\right) \\
& \frac{\partial W}{\partial h_{\text {evap }}}=\rho_{l} \frac{\pi}{4}\left(\frac{d_{\text {evap }}^{2}}{m_{\text {comp }}}\right)
\end{aligned}
$$

Where $\delta W$ presents the uncertainty in the ethanol adsorption uptake measurements, $\delta d_{\text {evap }}$ stands for uncertainty of the evaporator diameter and $\delta m_{\text {evap }}$ is the uncertainty of sample mass measurements whilst $\delta h_{\text {evap }}$ is the uncertainty ethanol level height measurements inside the evaporator using the digital microscope. The symbols $d_{\text {evap }}$, $m_{\text {comp }}$, and $h_{\text {evap }}$ represent the diameter of evaporator, composite sample mass, and height of ethanol level inside of the evaporator, respectively. The detailed specifications are as follows; $d_{\text {evap }}=6.8 \mathrm{~mm}, \delta d_{\text {evap }}=0.15 \mathrm{~mm}, m_{\text {comp }}=1.97 \mathrm{~g}$ and $\delta m_{\text {comp }}=0.01 \mathrm{~g}$ and $\delta h_{\text {evap }}=0.01 \mathrm{~mm}$. Using equation (3), the uncertainty of the ethanol adsorption uptake measurements has been found to be varying from 4.4 to $5.6 \%$.

\section{Results and discussion}

The Dubinin Radushkevich (D-R) and Dubinin Astakhov (D-A) equations have been used, respectively, to fit adsorption isotherms of composite A (50\% Maxsorb III, $40 \%$ 
EG, $10 \%$ binder) and composite C (70\% Maxsorb III, 20\% EG, 10\% binder) as given by Eq. (2) and Eq. (3) below.

$$
\begin{aligned}
& W=W_{o} \exp \left[-\left(\frac{R_{g} T}{E} \ln \left(\frac{P_{s}}{P}\right)\right)^{2}\right] \\
& W=W_{o} \exp \left[-\left(\frac{R_{g} T}{E} \ln \left(\frac{P_{s}}{P}\right)\right)^{n}\right]
\end{aligned}
$$

Where $W$ is adsorption uptake in $\mathrm{kg} \mathrm{kg}^{-1}, W_{0}$ is the maximum adsorption uptake $\mathrm{kg} \mathrm{kg}^{-1}$, $P$ stands for equilibrium pressure $\mathrm{kPa}$, and $P_{s}$ is the saturation pressure corresponding to the adsorption temperature $T$. The parameter $E$ is an adsorption characteristics that depends on adsorbent/refrigerant pair $\mathrm{kJ} \mathrm{kg}^{-1} \mathrm{~K}^{-1}$ and $n$ is an exponent of the D-A equation (Eq. 3). Numerical values of $W_{0}, E$ and $n$ for composite A/ethanol and composite C/ethanol pairs have been furnished in Table 2. Fig. 5(a) shows adsorption isobars of ethanol onto composite A at evaporation temperatures of $5{ }^{\circ} \mathrm{C}, 10{ }^{\circ} \mathrm{C}$ and $15^{\circ} \mathrm{C}$, the fitting of D-R equation is also superimposed on the same figure. The plot of adsorption uptake versus adsorption temperatures at the same evaporation temperatures for composite C/ethanol pair is also shown in Fig. 5(b). Adsorption equilibrium uptake predicted by D-A equation of composite C/ethanol pair is also presented on the same figure. It can be seen from Figs. 5(a) and 5(b) that there is a good agreement between experimentally measured adsorption equilibrium data and those predicted using D-R and D-A equations. It is also worth mentioning that the maximum adsorption uptake of composite A (50\% Maxsorb III, 40\% EG, 10\% binder) and composite C (70\% Maxsorb III, 20\% EG, $10 \%$ binder) are, respectively, 0.61 and $0.89 \mathrm{~kg} \mathrm{~kg}^{-1}$ which about $50 \%$ and $74 \%$ of maximum adsorption uptake of Maxsorb III/ethanol pair [8]. This is clear 
evidence that the binder doesn't sacrifice the adsorption capacity of Maxsorb III of the consolidated composites. Figs. 6(a) and 6(b) show the volumetric adsorption isotherms of composite A/ethanol and composite C/ethanol pairs. The volumetric uptake is estimated using the packing density of each composite. It can be seen from Figs. 6(a) and 6(b) that, composite A has the ability to adsorb about $325 \mathrm{~kg} \mathrm{~m}^{-3}$ of ethanol at adsorption temperature of $30{ }^{\circ} \mathrm{C}$ whilst composite $\mathrm{C}$ can adsorb ethanol as high as 380 $\mathrm{kg} \mathrm{m}^{-3}$ at the same adsorption temperature. Fig. 7 shows the comparison between volumetric uptake difference of adsorption cooling cycles employing composite C/ethanol (solid line ABCD) and Maxsorb III/ethanol (dashed line abcd) pairs at the evaporator, adsorption and desorption temperatures of 7,30 and $80{ }^{\circ} \mathrm{C}$, respectively. The packing density of Maxsorb III powder has been measured using Micromeritics: GeoPyc 1360 Pycnometer provided by Micromeritics Instrument Corporation and found to be $290 \mathrm{~kg} \mathrm{~m}^{-3}$. It can be seen from Fig. 7 that, volumetric uptake difference of composite C/ethanol pair is about 21\% higher than that of Maxsorb III/ethanol.

\section{Thermal conductivity measurements}

The thermal conductivity of the prepared composite adsorbents has been measured using The NETZSCH LFA 457 MicroFlash system. Fig. 8 shows the schematic diagram of the measuring part of the apparatus. Adsorbent samples have been prepared as coins like to fit the sample holder of the apparatus. The measurements have been conducted at atmospheric condition where the temperature is kept constant at $25{ }^{\circ} \mathrm{C}$. The emitted laser pulse hits the lower surface of the sample where the heat generated is transferred by conduction (one-dimensional) through the sample. The temperature rise of the upper side of the sample has been detected using InSb- or MCT-infrared detector. The 
temperature increase of the upper side as a function of time allows the determination of the thermal diffusivity according to the following equation [28]

$$
\alpha=0.1388 \frac{L^{2}}{t_{0.5}}
$$

Where $L$ is the thickness of the test piece and $t_{0.5}$ is the time at $50 \%$ of the temperature increase, measured at the rear of the test piece. Thermal conductivity of the composite adsorbent can be estimated using Eq. (5) below;

$k=\alpha \rho C_{p}$

Where $k$ is the thermal conductivity $\left(\mathrm{W} \mathrm{m}^{-1} \mathrm{~K}^{-1}\right), \alpha$ is the thermal diffusivity of composite adsorbents $\left(\mathrm{m}^{2} \mathrm{~s}^{-1}\right), \rho$ presents the adsorbent density $\left(\mathrm{kg} \mathrm{m}^{-3}\right)$ and $C_{p}$ stands for specific heat $\left(\mathrm{J} \mathrm{kg}^{-1} \mathrm{~K}^{-1}\right)$. The specific heat of composite adsorbents can be estimated according to Eq. (6) below;

$C_{p}=\left(\frac{1}{m_{\text {composite }}}\right) \sum m_{i} C_{P, i}$

Where $i$ presents the constituent of composite adsorbents including Maxsorb III, expanded graphite and binder, whilst $m$ stands for the mass of constitute. Fig. 9 shows the plots of thermal diffusivity versus the percentage of expanded graphite at a temperature of $25^{\circ} \mathrm{C}$ and atmospheric condition. It can be seen from Fig. 9 that thermal diffusivity increases with the increase of the percentage of expanded graphite. The percentage of binder is kept constant at $10 \%$ whilst the percentage of expanded graphite changed from $10 \%$ to $40 \%$ and the percentage of Maxsorb III ranging from $80 \%$ to $50 \%$. It should be highlighted that, the packing density composite adsorbents also increases 
with the increases of percentage of expanded graphite as shown in Fig. 9. Thermal conductivity of composite adsorbents at different percentages of expanded graphite is estimated according to Eq. (5) and the results are depicted in Fig. 10. Experimental results show that thermal conductivity increases from $0.15 \mathrm{~W} \mathrm{~m}^{-1} \mathrm{~K}^{-1}$ at a percentage of expanded graphite of $10 \%$ and reaches a value of $0.61 \mathrm{~W} \mathrm{~m}^{-1} \mathrm{~K}^{-1}$ at a percentage of expanded graphite of $40 \%$. The thermal conductivity of Maxsorb III powder has been measured at ambient condition using the C-Therm TCi system and found to be $0.066 \mathrm{~W}$ $\mathrm{m}^{-1} \mathrm{~K}^{-1}$. Therefore, the percentage of improvement in thermal conductivity compared to that of Maxsorb III (powder) ranging from $100 \%$ to about $800 \%$. Pino et al. [29] also observed that equivalent thermal conductivity of 4A-zeolite-based composites increases with the increase of percentage of graphite. Plot of thermal conductivity of composite adsorbent (50\% Maxsorb III, 40\% EG, 10\% binder) versus the packing density is shown in Fig. 11. As can be seen from Fig. 11, for the same adsorbent composition, thermal conductivity increases with the increase of packing density. The highest value of thermal conductivity is found to be $0.74 \mathrm{~W} \mathrm{~m}^{-1} \mathrm{~K}^{-1}$ at a composite packing density of $650 \mathrm{~kg} \mathrm{~m}^{-3}$ which is about 10 times that of Maxsorb III powder. It should be mentioned that, larger packing density leads to higher thermal conductivity but lower permeability. Therefore, it is important to investigate the permeability and estimate the optimum combination between thermal conductivity and permeability of the composite adsorbent. 


\section{Conclusions}

Consolidated composite adsorbents which are combinations of Maxsorb III, expanded graphite, and binder have been developed. Adsorption uptakes of ethanol onto prepared adsorbents have been experimentally investigated. The Dubinin Radushkevich (D-R) and Dubinin Astakhov (D-A) equations have been used to fit adsorption uptake measurement. It is found that $1 \mathrm{~kg}$ of consolidated composite (70\% Maxsorb III, 20\% EG, $10 \%$ binder) able to adsorb $0.89 \mathrm{~kg}$ of ethanol whilst adsorption capacity of adsorbent composite (50\% Maxsorb III, $40 \%$ EG, $10 \%$ binder) is $0.61 \mathrm{~kg} \mathrm{~kg}^{-1}$. Experimental results also show that the thermal conductivity of composite adsorbent increases with the increase of percentage of expanded graphite. Among the tested samples, the highest value of thermal conductivity is found to be $0.74 \mathrm{~W} \mathrm{~m}^{-1} \mathrm{~K}^{-1}$ at composite packing density of $650 \mathrm{~kg} \mathrm{~m}^{-3}$, which is about 10 times that of Maxsorb III powder.

\section{Acknowledgements}

This work was financially supported by Japan Science and Technology Agency (JST), Core Research Evolution Science and Technology (CREST). 


\section{References}

[1] I.I. El-Sharkawy, H. AbdelMeguid, B.B. Saha, Towards an optimal performance of adsorption chillers: Reallocation of adsorption/desorption cycle times, International Journal of Heat and Mass Transfer, 63 (2013) 171-182.

[2] Y.I. Aristov, G. Restuccia, G. Cacciola, V.N. Parmon, A family of new working materials for solid sorption air conditioning systems, Applied Thermal Engineering, 22 (2002) 191-204.

[3] S.K. Henninger, F. Jeremias, H. Kummer, P. Schossig, H.-M. Henning, Novel Sorption Materials for Solar Heating and Cooling, Energy Procedia, 30 (2012) 279-288.

[4] I.I. El-Sharkawy, K. Kuwahara, B.B. Saha, S. Koyama, K.C. Ng, Experimental investigation of activated carbon fibers/ethanol pairs for adsorption cooling system application, Applied Thermal Engineering, 26 (2006) 859-865.

[5] İ. Solmuş, C. Yamalı, B. Kaftanoğlu, D. Baker, A. Çağlar, Adsorption properties of a natural zeolite-water pair for use in adsorption cooling cycles, Applied Energy, 87 (2010) 2062-2067.

[6] K. Uddin, I.I. El-Sharkawy, T. Miyazaki, B.B. Saha, S. Koyama, H.-S. Kil, J. Miyawaki, S.-H. Yoon, Adsorption characteristics of ethanol onto functional activated carbons with controlled oxygen content, Applied Thermal Engineering, 72 (2014) 211218.

[7] I.I. El-Sharkawy, K. Uddin, T. Miyazaki, B. Baran Saha, S. Koyama, H.-S. Kil, S.H. Yoon, J. Miyawaki, Adsorption of ethanol onto phenol resin based adsorbents for developing next generation cooling systems, International Journal of Heat and Mass Transfer, 81 (2015) 171-178.

[8] I.I. El-Sharkawy, K. Uddin, T. Miyazaki, B.B. Saha, S. Koyama, J. Miyawaki, S.-H. Yoon, Adsorption of ethanol onto parent and surface treated activated carbon powders, International Journal of Heat and Mass Transfer, 73 (2014) 445-455.

[9] Y.I. Aristov, Challenging offers of material science for adsorption heat transformation: A review, Applied Thermal Engineering, 50 (2013) 1610-1618.

[10] S.K. Henninger, F.P. Schmidt, H.M. Henning, Water adsorption characteristics of 
novel materials for heat transformation applications, Applied Thermal Engineering, 30 (2010) 1692-1702.

[11] Q. Cui, G. Tao, H. Chen, X. Guo, H. Yao, Environmentally benign working pairs for adsorption refrigeration, Energy, 30 (2005) 261-271.

[12] A. Chakraborty, B. Sun, An adsorption isotherm equation for multi-types adsorption with thermodynamic correctness, Applied Thermal Engineering, 72 (2014) 190-199.

[13] T. Miyazaki, A. Akisawa, B.B. Saha, I.I. El-Sharkawy, A. Chakraborty, A new cycle time allocation for enhancing the performance of two-bed adsorption chillers, International Journal of Refrigeration, 32 (2009) 846-853.

[14] Y.I. Aristov, A. Sapienza, D.S. Ovoshchnikov, A. Freni, G. Restuccia, Reallocation of adsorption and desorption times for optimisation of cooling cycles, International Journal of Refrigeration, 35 (2012) 525-531.

[15] G. Cacciola, G. Restuccia, L. Mercadante, Composites of activated carbon for refrigeration adsorption machines, Carbon, 33 (1995) 1205-1210.

[16] Z. Jin, B. Tian, L. Wang, R. Wang, Comparison on thermal conductivity and permeability of granular and consolidated activated carbon for refrigeration, Chinese Journal of Chemical Engineering, 21 (2013) 676-682.

[17] Z. Tamainot-Telto, R.E. Critoph, Monolithic carbon for sorption refrigeration and heat pump applications, Applied Thermal Engineering, 21 (2001) 37-52.

[18] L.W. Wang, Z. Tamainot-Telto, R. Thorpe, R.E. Critoph, S.J. Metcalf, R.Z. Wang, Study of thermal conductivity, permeability, and adsorption performance of consolidated composite activated carbon adsorbent for refrigeration, Renewable Energy, 36 (2011) 2062-2066.

[19] L.W. Wang, S.J. Metcalf, R.E. Critoph, R. Thorpe, Z. Tamainot-Telto, Development of thermal conductive consolidated activated carbon for adsorption refrigeration, Carbon, 50 (2012) 977-986.

[20] X. Zheng, L.W. Wang, R.Z. Wang, T.S. Ge, T.F. Ishugah, Thermal conductivity, pore structure and adsorption performance of compact composite silica gel, 
International Journal of Heat and Mass Transfer, 68 (2014) 435-443.

[21] X. Py, E. Daguerre, D. Menard, Composites of expanded natural graphite and in situ prepared activated carbons, Carbon, 40 (2002) 1255-1265.

[22] S.L. Li, Z.Z. Xia, J.Y. Wu, J. Li, R.Z. Wang, L.W. Wang, Experimental study of a novel $\mathrm{CaCl} 2 /$ expanded graphite-NH3 adsorption refrigerator, International Journal of Refrigeration, 33 (2010) 61-69.

[23] B. Tian, Z.Q. Jin, L.W. Wang, R.Z. Wang, Permeability and thermal conductivity of compact chemical and physical adsorbents with expanded natural graphite as host matrix, International Journal of Heat and Mass Transfer, 55 (2012) 4453-4459.

[24] T.-H. Eun, H.-K. Song, J. Hun Han, K.-H. Lee, J.-N. Kim, Enhancement of heat and mass transfer in silica-expanded graphite composite blocks for adsorption heat pumps: Part I. Characterization of the composite blocks, International Journal of Refrigeration, 23 (2000) 64-73.

[25] K. Fujioka, K. Hatanaka, Y. Hirata, Composite reactants of calcium chloride combined with functional carbon materials for chemical heat pumps, Applied Thermal Engineering, 28 (2008) 304-310.

[26] I.I. El-Sharkawy, B.B. Saha, S. Koyama, J. He, K.C. Ng, C. Yap, Experimental investigation on activated carbon-ethanol pair for solar powered adsorption cooling applications, International Journal of Refrigeration, 31 (2008) 1407-1413.

[27] J.R. Taylor, An introduction to error analysis, Library of Congress Cataloging-inPublication Data, USA, 1997.

[28] W.J. Parker, R.J. Jenkins, C.P. Butler, G.L. Abbott, Flash method of determining thermal diffusivity, heat capacity, and thermal conductivity, Journal of Applied Physics, 32 (1961) 1679-1684.

[29] L. Pino, Y. Aristov, G. Cacciola, G. Restuccia, Composite materials based on zeolite 4A for adsorption heat pumps, Adsorption, 3 (1996) 33-40. 


\section{List of Tables}

\section{Table 1}

Composition and porous properties of the developed consolidated adsorbent samples.

Table 2

Isotherm parameters of ethanol adsorption onto of the studied composites. 


\section{List of Figures:}

Fig. 1(a). Production process of developed composite adsorbents.

Fig.1 (b). A pictorial view of developed composite adsorbents.

Fig. 2. Nitrogen adsorption/desorption isotherm onto various composites.

Fig. 3. The pore size distribution of various consolidated composite samples.

Fig. 4. Schematic diagram of the experimental apparatus for measuring adsorption uptake of ethanol onto composite adsorbents.

Fig. 5(a). Adsorption isobars of ethanol onto composite A (50\% Maxsorb III, 40\% EG, $10 \%$ binder) with packing density of $517 \mathrm{~kg} \mathrm{~m}^{-3}$ (error bars of uptake is $\pm 5 \%$ ).

Fig. 5(b). Adsorption isobars of ethanol onto composite C (70\% Maxsorb III, 20\% EG, $10 \%$ binder) with packing density of $446 \mathrm{~kg} \mathrm{~m}^{-3}$ (error bars of uptake is $\pm 5 \%$ ).

Fig. 6(a). Predicted volumetric adsorption isotherms of ethanol onto composite adsorbent A (50\% Maxsorb III, 40\% EG, 10\% binder) with packing density of $517 \mathrm{~kg} \mathrm{~m}^{-3}$.

Fig. 6(b). Predicted volumetric adsorption isotherms of ethanol onto composite adsorbent C (70\% Maxsorb III, 20\% EG, 10\% binder) with packing density of $446 \mathrm{~kg} \mathrm{~m}^{-3}$.

Fig. 7. Comparison between volumetric adsorption uptake difference of adsorption cooling cycles using Maxsorb III/ethanol and composite C/ethanol pairs at evaporator, adsorption and desorption temperatures of 7,30 and $80^{\circ} \mathrm{C}$, respectively.

Fig. 8. Schematic design of LFA 457 MicroFlash system.

Fig. 9. Plots of thermal diffusivity versus the percentage of expanded graphite.

Fig. 10. Plots of thermal conductivity versus the percentage of expanded graphite.

Fig. 11. Plots of thermal conductivity of composite A (50\% Maxsorb III, 40\% EG, 10\% binder) versus the packing density. 
Table 1

Composition and porous properties of the developed consolidated adsorbent samples.

\begin{tabular}{|c|c|c|}
\hline Sample composition & $\begin{array}{c}\text { Total surface area } \\
\qquad\left[\mathrm{m}^{2} \mathrm{~g}^{-1}\right]\end{array}$ & $\begin{array}{l}\text { Total pore } \\
\text { volume } \\
{\left[\mathrm{cm}^{\mathbf{3}} \mathbf{g}^{-1}\right]}\end{array}$ \\
\hline A: $50 \%$ Maxsorb III, $40 \%$ EG, $10 \%$ binder & $1420 \pm 30$ & 0.787 \\
\hline B: $60 \%$ Maxsorb III, 30\% EG, $10 \%$ binder & $1907 \pm 21$ & 0.948 \\
\hline C: $70 \%$ Maxsorb III, $20 \%$ EG, $10 \%$ binder & $2000 \pm 34$ & 1.094 \\
\hline D: $80 \%$ Maxsorb III, $10 \%$ EG, $10 \%$ binder & $2485 \pm 19$ & 1.210 \\
\hline
\end{tabular}


Table 2

Isotherm parameters of ethanol adsorption onto of the studied composites.

\begin{tabular}{cccc}
\hline Composite & $\mathbf{W}_{\mathbf{0}}\left[\mathbf{k g ~ k g} \mathbf{~ k}^{-\mathbf{1}}\right]$ & $\mathbf{E}\left[\mathbf{k J ~ k g} \mathbf{~}^{-\mathbf{1}}\right]$ & $\mathbf{n}[-]$ \\
\hline A: 50\% Maxsorb III, 40\% EG, 10\% binder & 0.61 & 125 & 2 \\
C: 70\% Maxsorb III, 20\% EG, 10\% binder & 0.89 & 119 & 1.8 \\
\hline
\end{tabular}




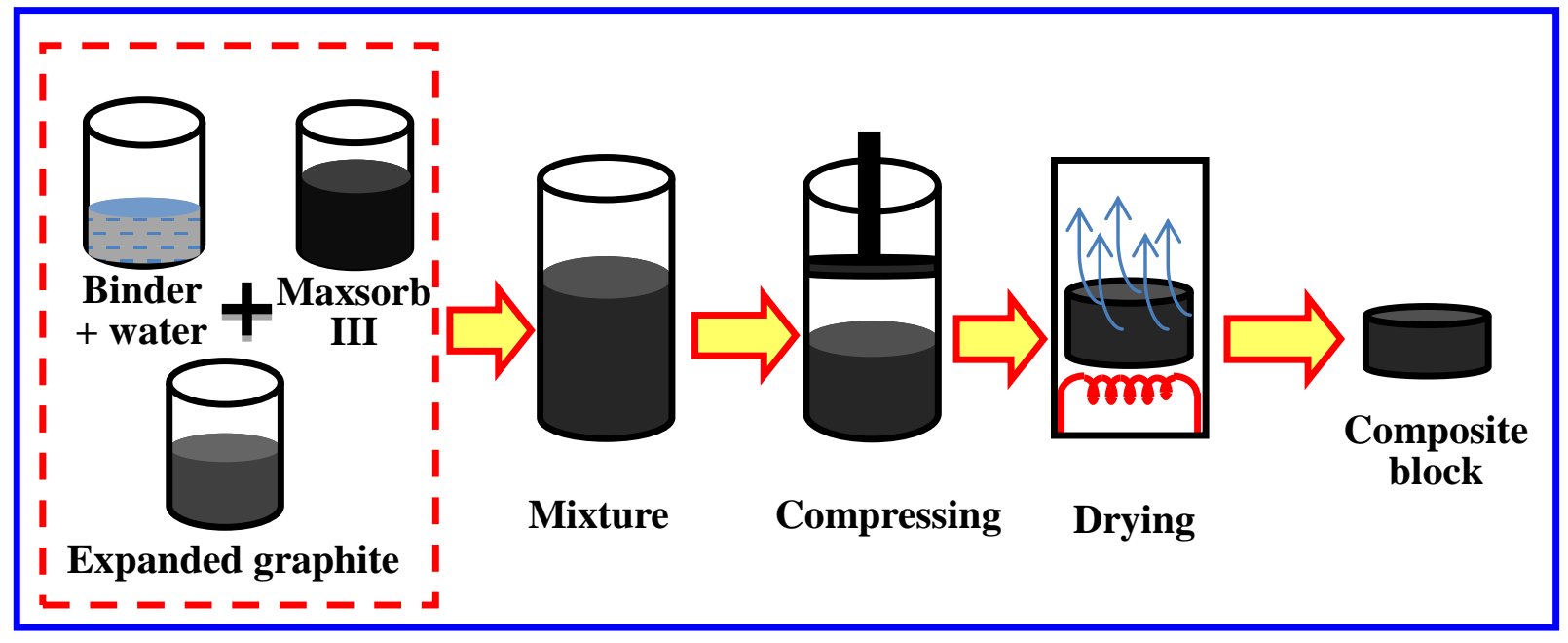

Fig. 1(a). Production process of developed composite adsorbents.

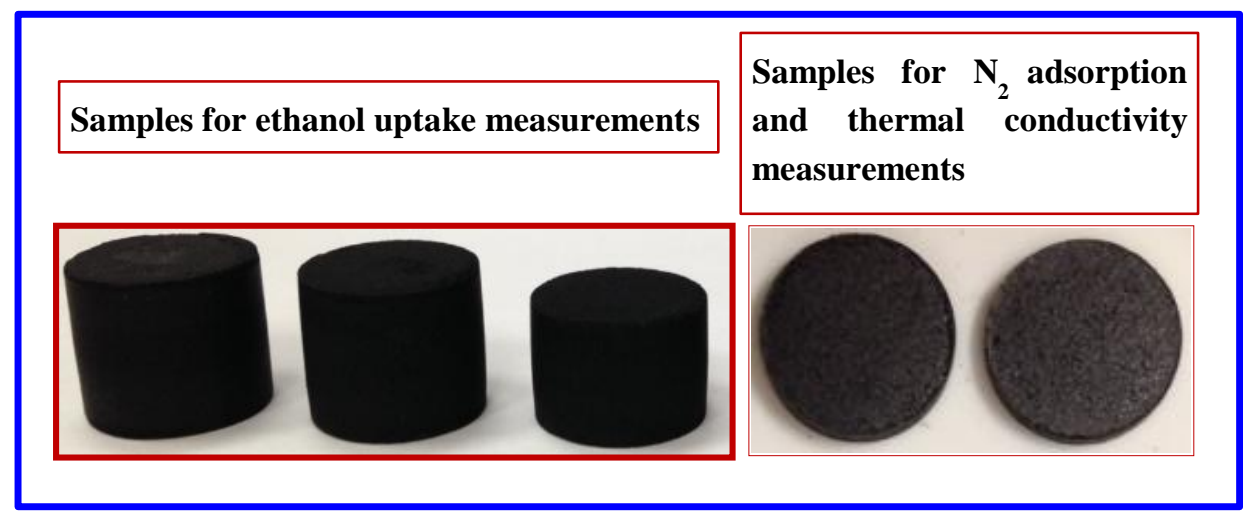

Fig.1 (b). A pictorial view of developed composite adsorbents. 


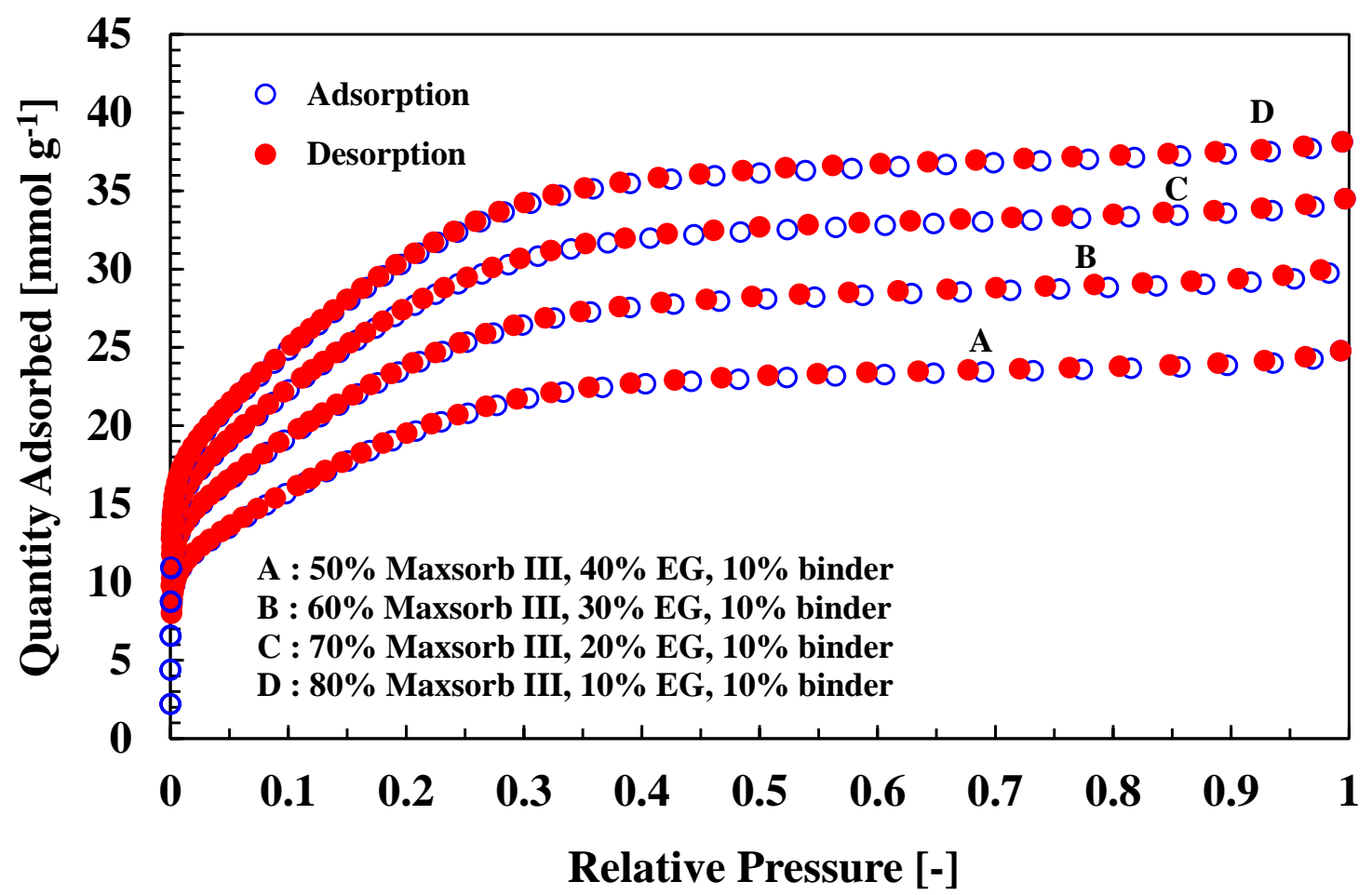

Fig. 2. Nitrogen adsorption/desorption isotherm onto various composites. 


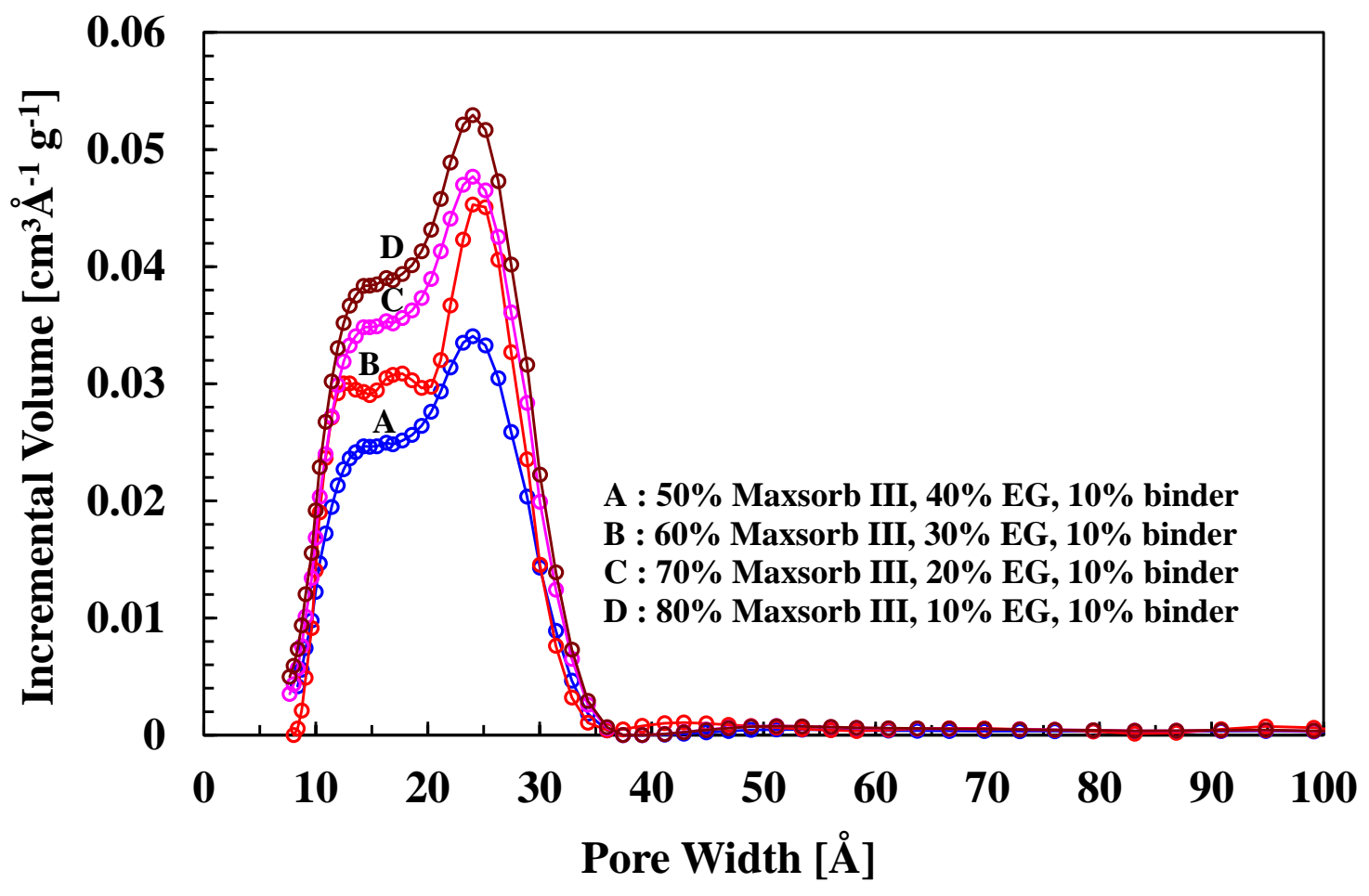

Fig. 3. The pore size distribution of various consolidated composite samples. 


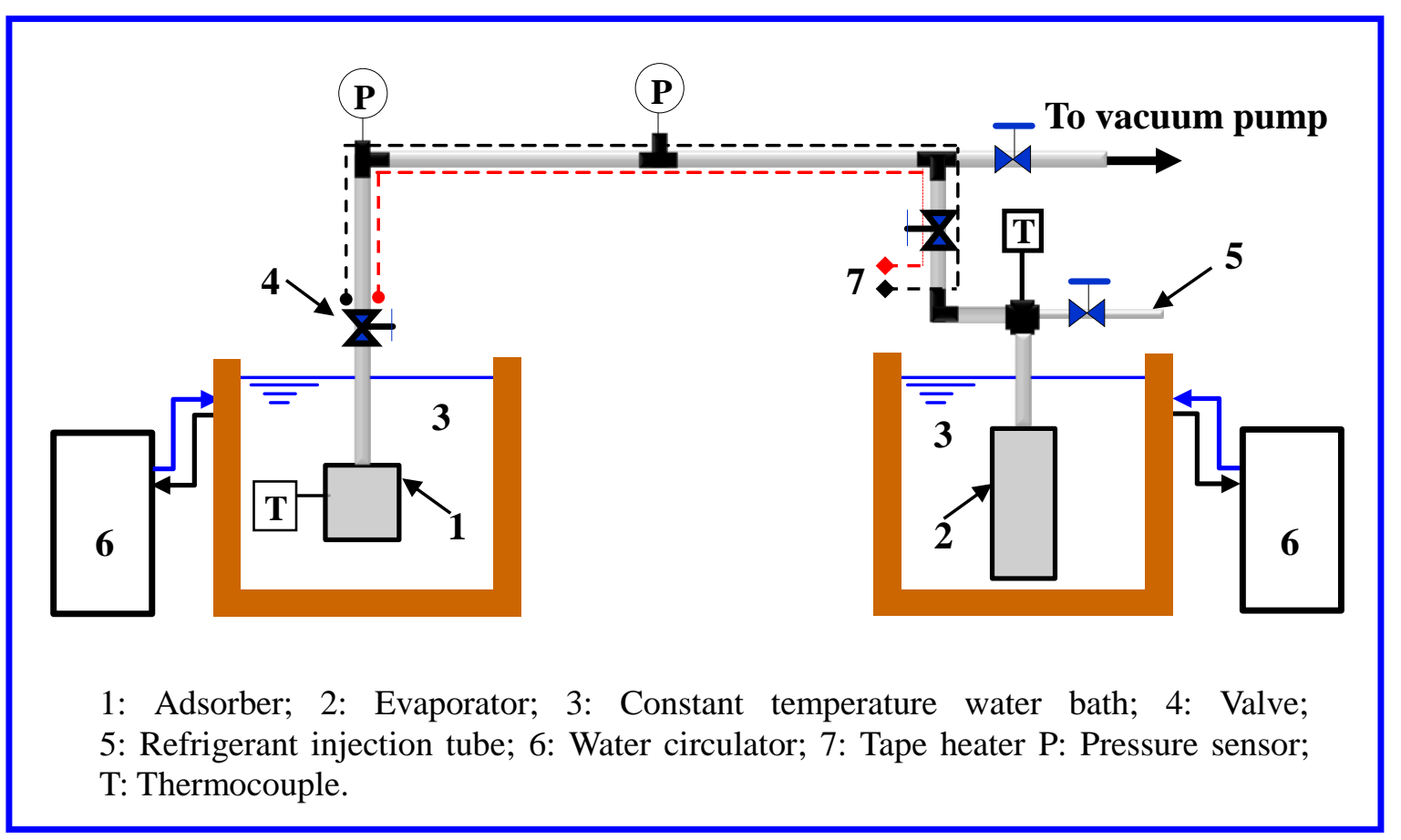

Fig. 4. Schematic diagram of the experimental apparatus for measuring adsorption uptake of ethanol onto composite adsorbents. 


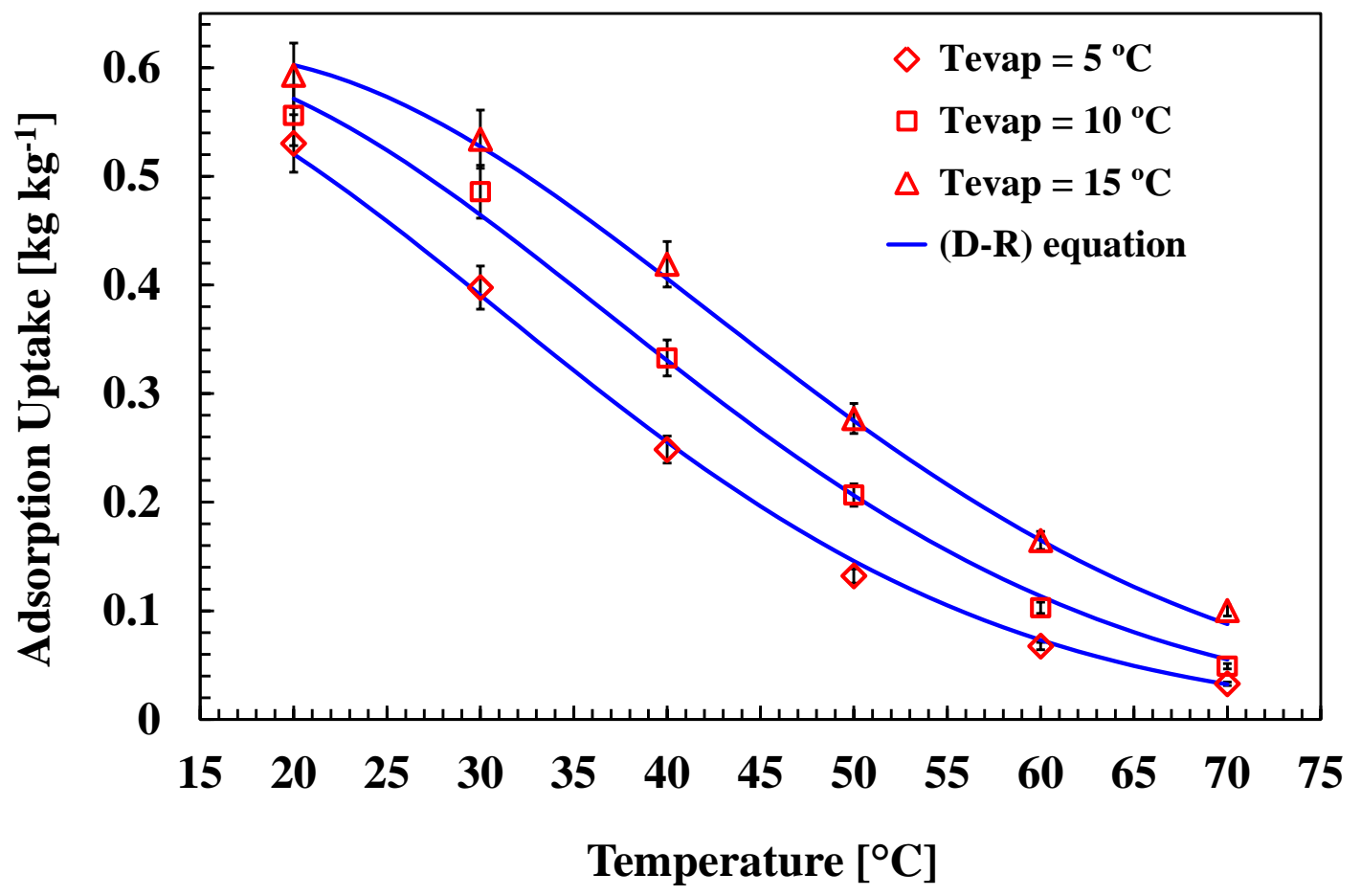

Fig. 5(a). Adsorption isobars of ethanol onto composite A (50\% Maxsorb III, 40\% EG, $10 \%$ binder) with packing density of $517 \mathrm{~kg} \mathrm{~m}^{-3}$ (error bars of uptake is $\pm 5 \%$ ). 


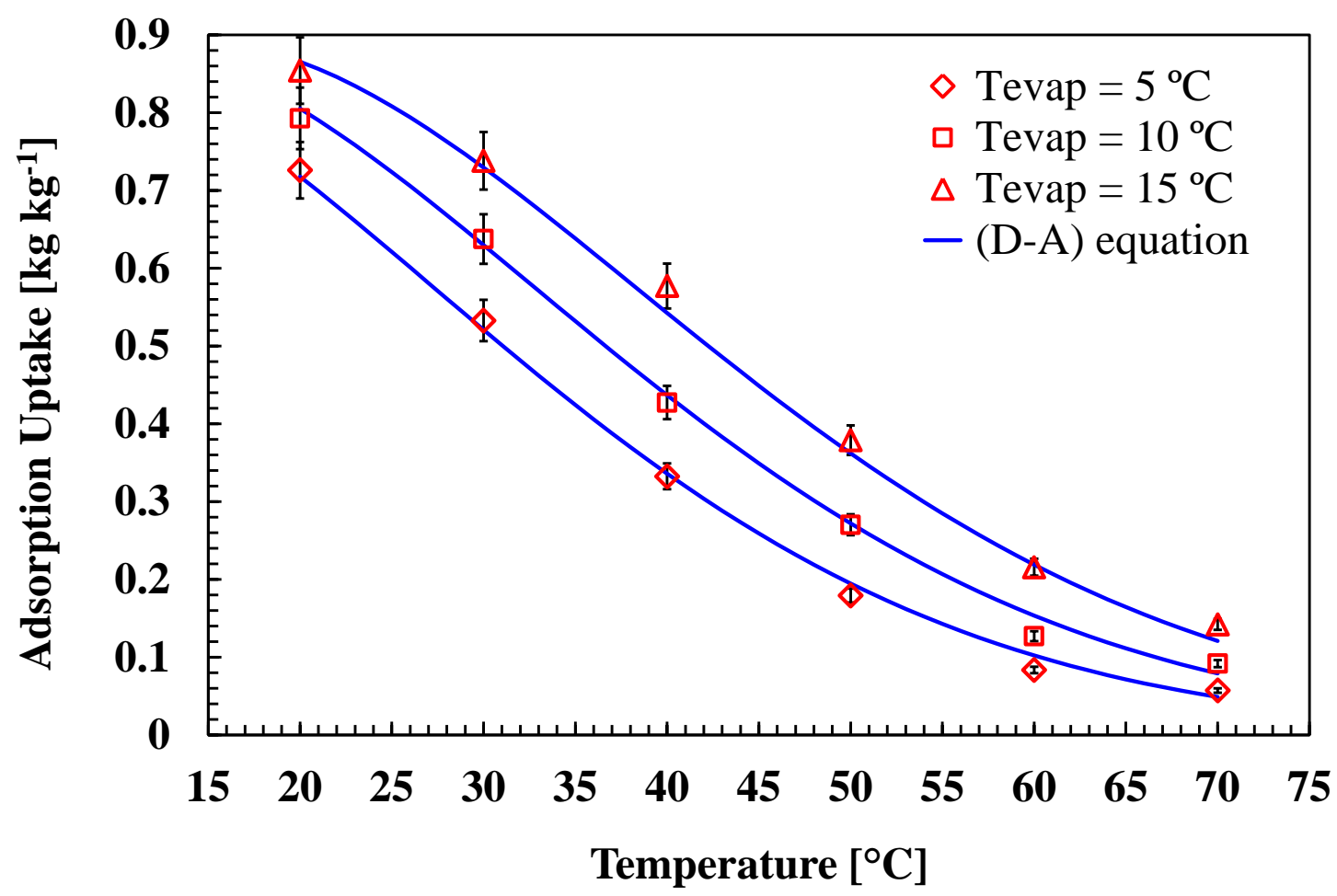

Fig. 5(b). Adsorption isobars of ethanol onto composite C (70\% Maxsorb III, 20\% EG, $10 \%$ binder) with packing density of $446 \mathrm{~kg} \mathrm{~m}^{-3}$ (error bars of uptake is $\pm 5 \%$ ). 


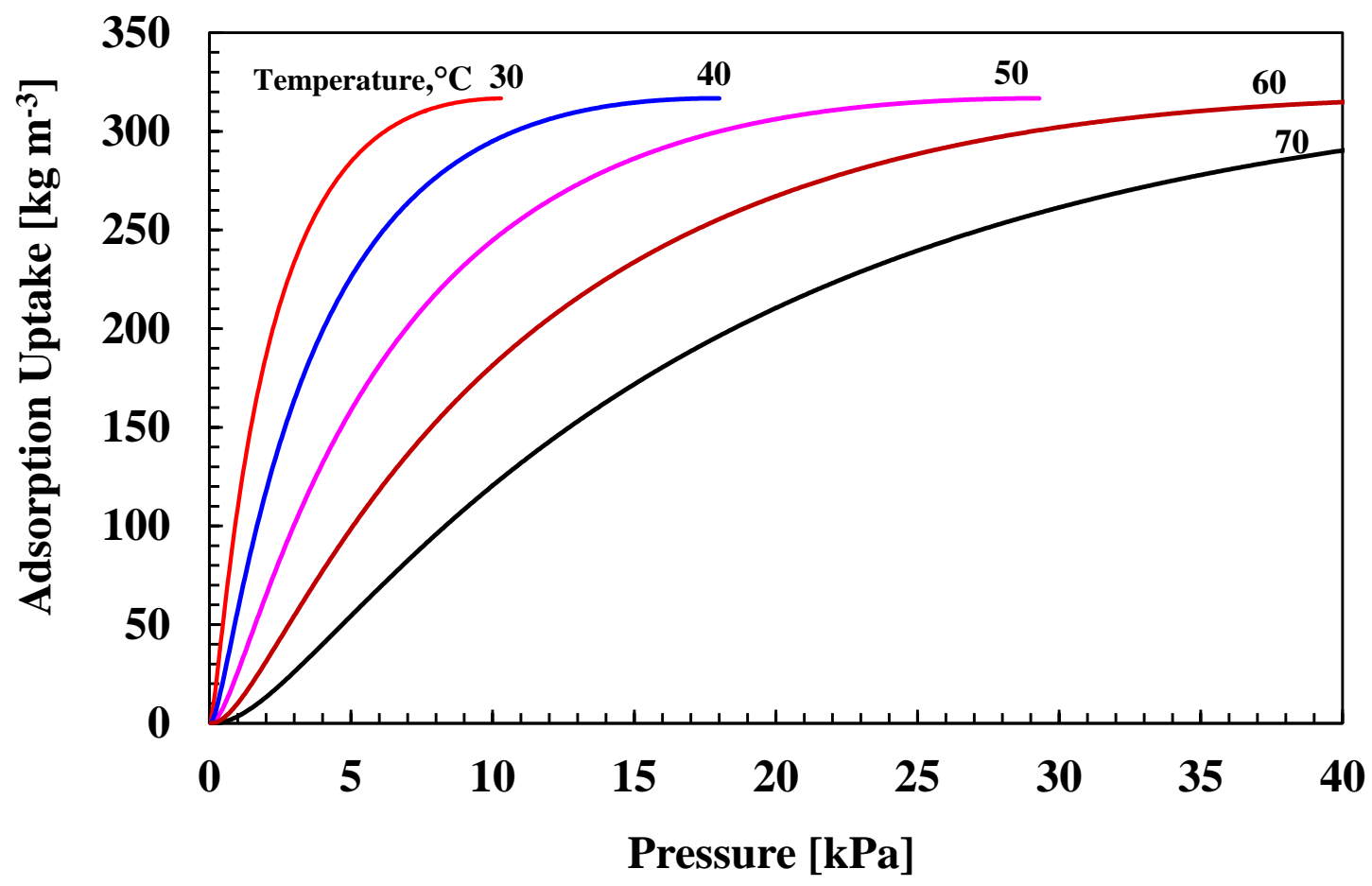

Fig. 6(a). Predicted volumetric adsorption isotherms of ethanol onto composite adsorbent A (50\% Maxsorb III, 40\% EG, 10\% binder) with packing density of $517 \mathrm{~kg} \mathrm{~m}^{-3}$. 


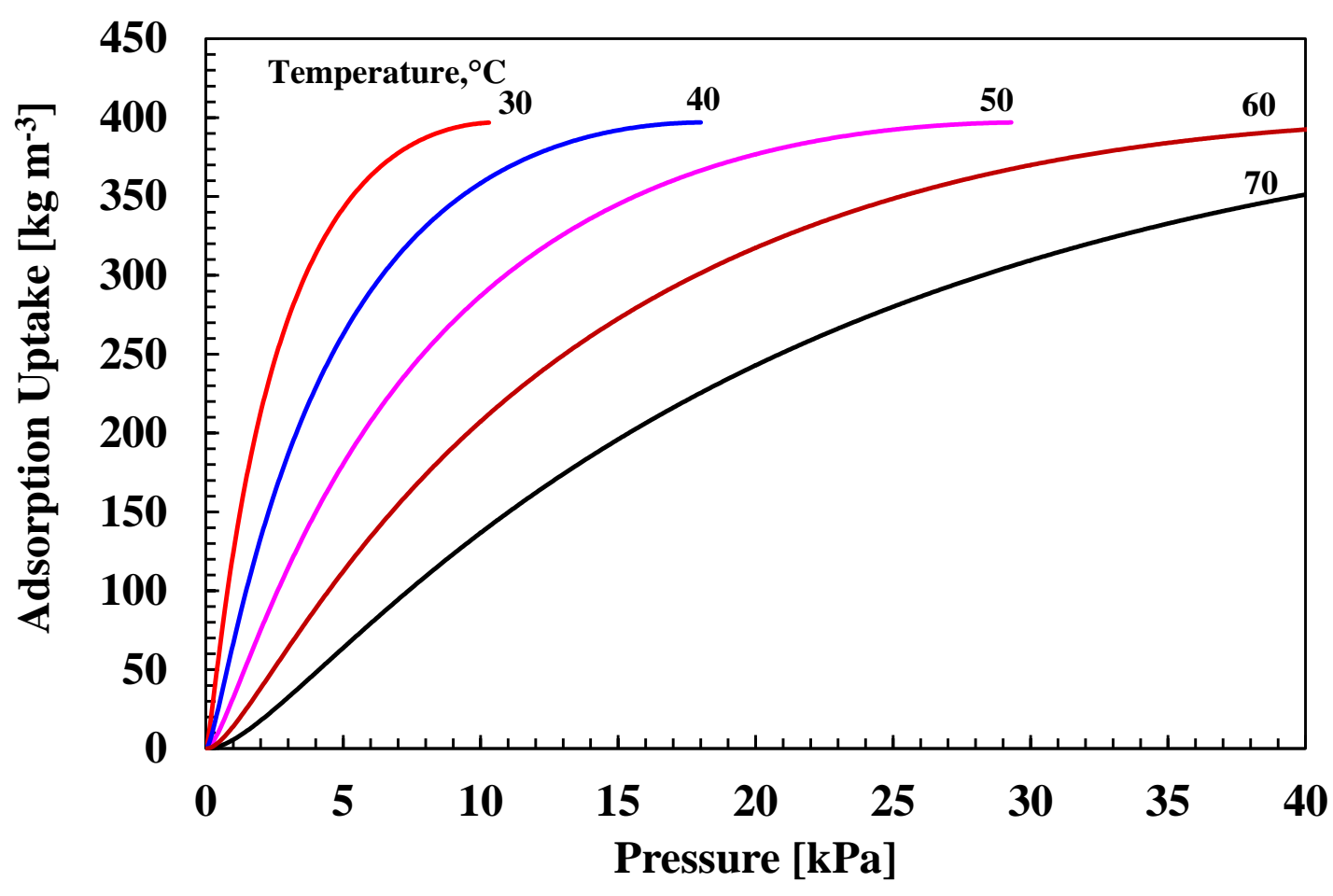

Fig. 6(b). Predicted volumetric adsorption isotherms of ethanol onto composite adsorbent C (70\% Maxsorb III, 20\% EG, 10\% binder) with packing density of $446 \mathrm{~kg} \mathrm{~m}^{-3}$. 


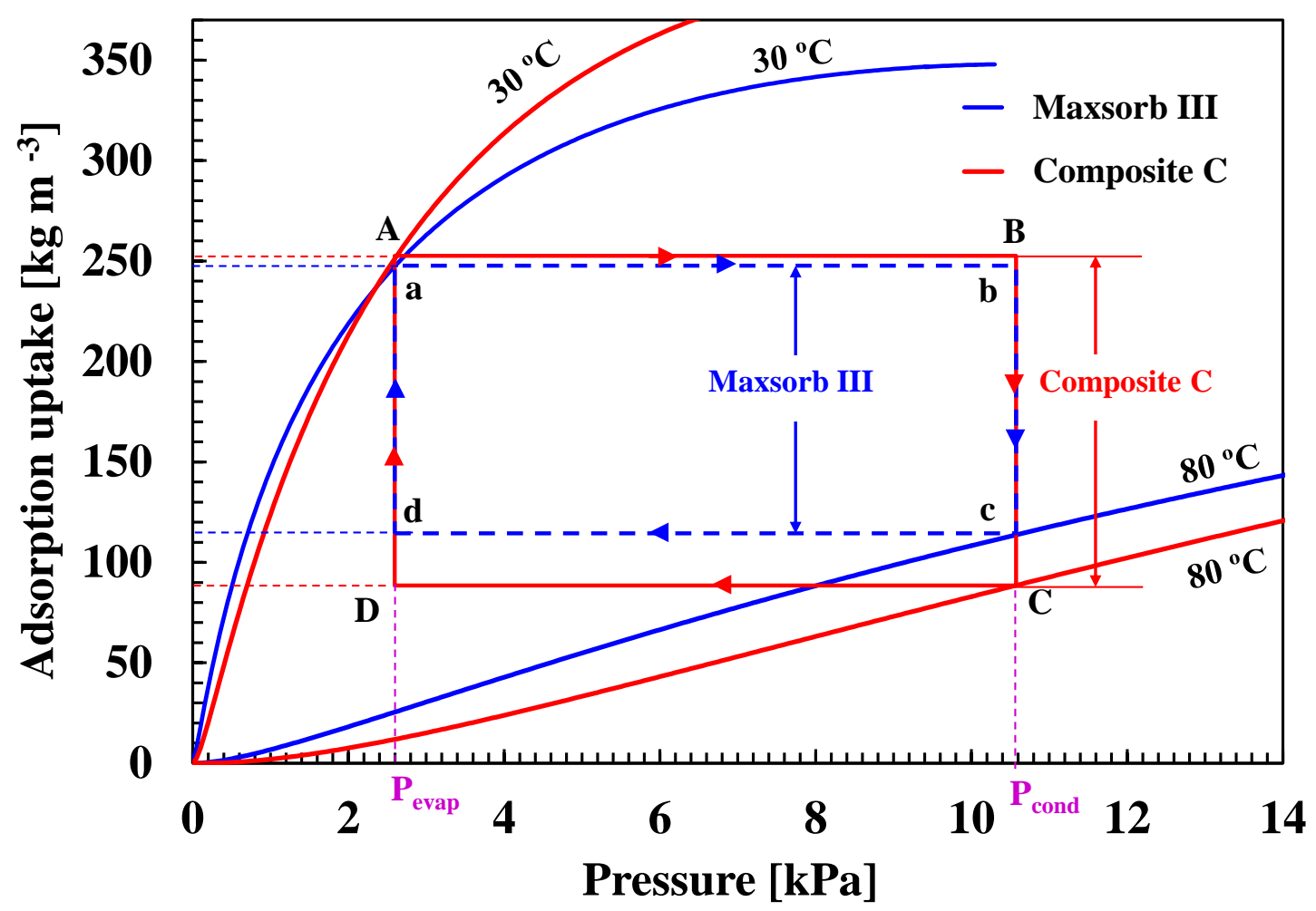

Fig. 7. Comparison between volumetric adsorption uptake difference of adsorption cooling cycles using Maxsorb III/ethanol and composite C/ethanol pairs at evaporator, adsorption and desorption temperatures of 7,30 and $80^{\circ} \mathrm{C}$, respectively. 


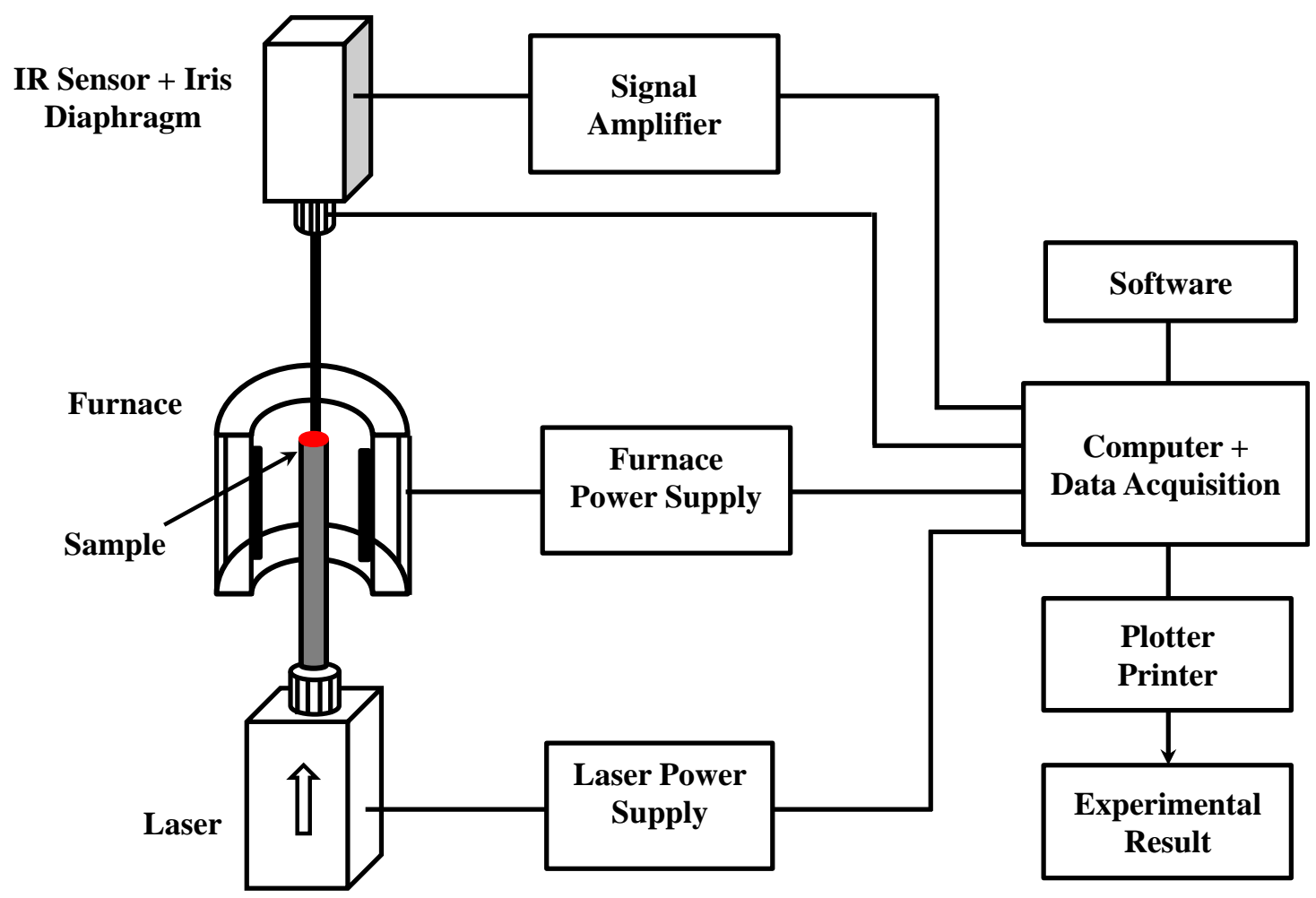

Fig. 8. Schematic design of LFA 457 MicroFlash system. 


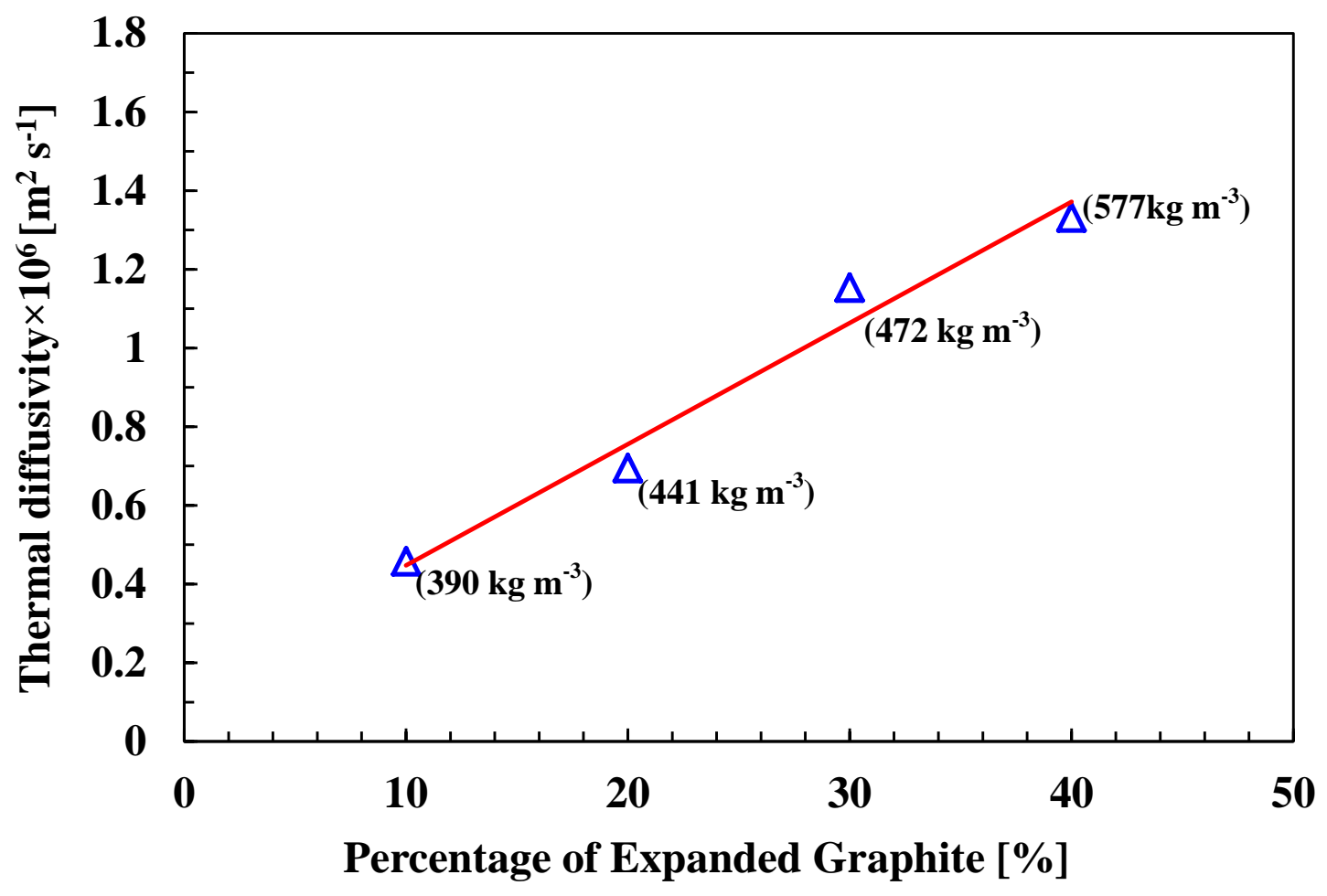

Fig. 9. Plots of thermal diffusivity versus the percentage of expanded graphite. 


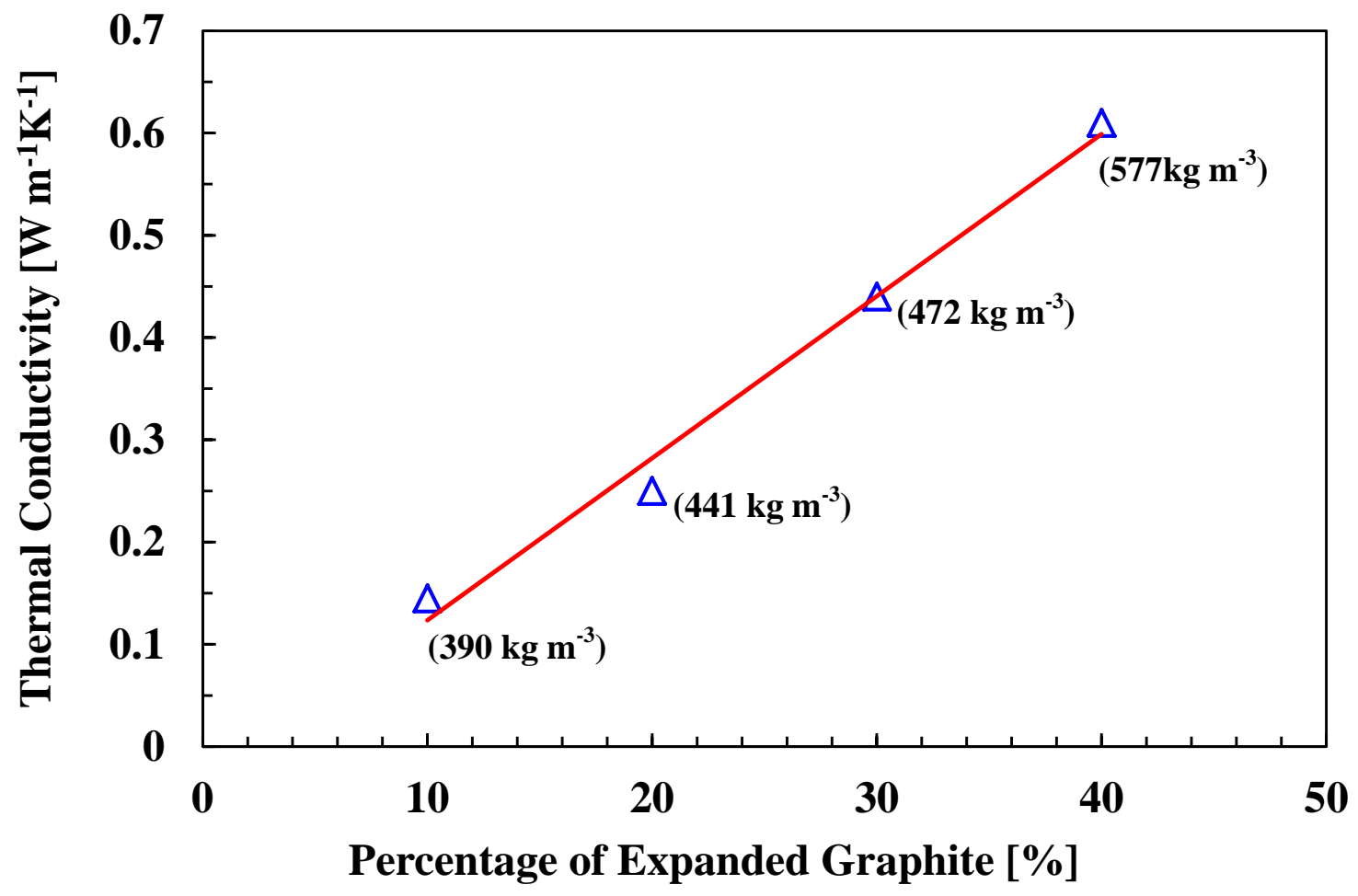

Fig. 10. Plots of thermal conductivity versus the percentage of expanded graphite. 


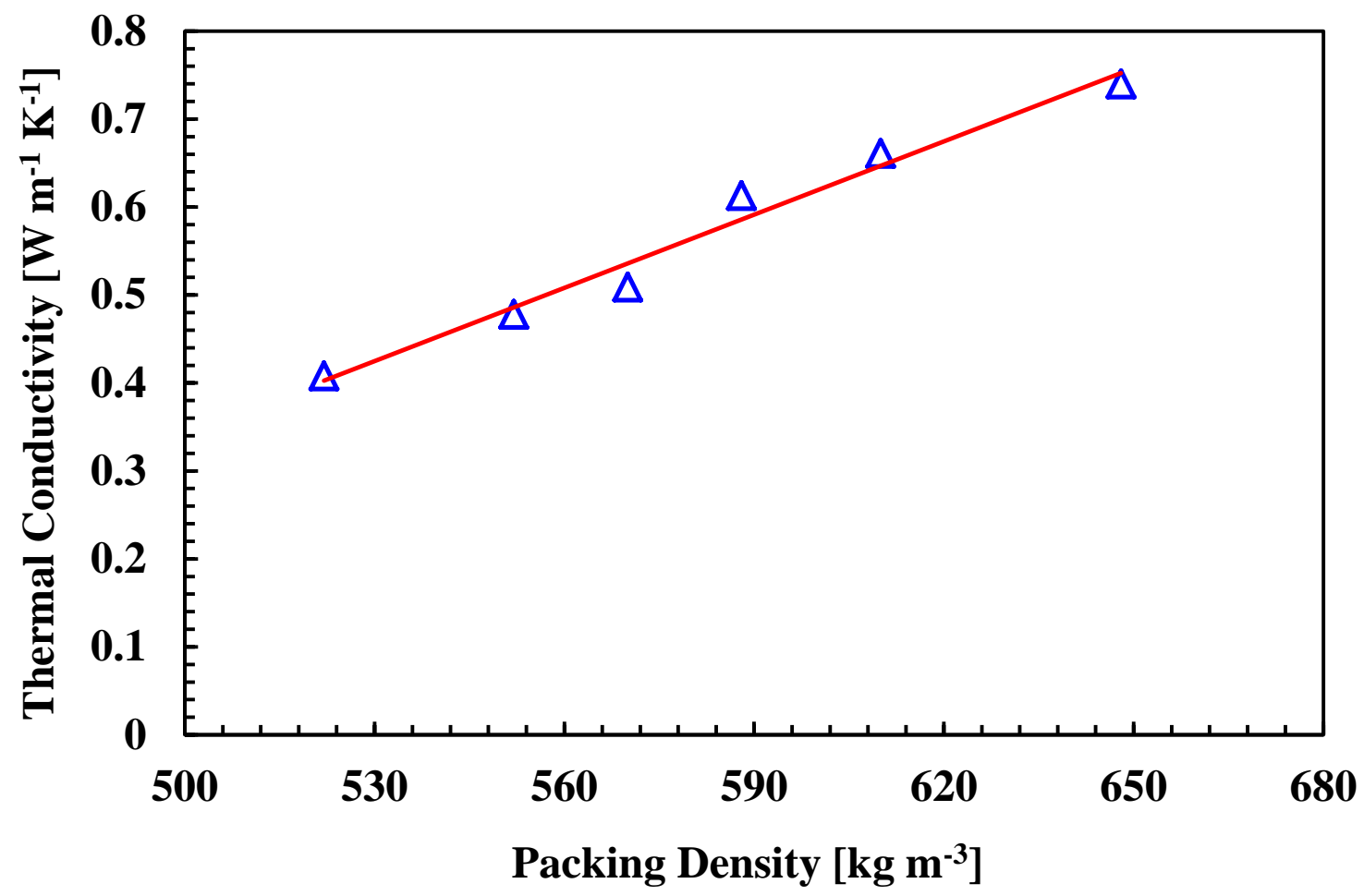

Fig. 11. Plots of thermal conductivity of composite A (50\% Maxsorb III, $40 \%$ EG, $10 \%$ binder) versus the packing density. 